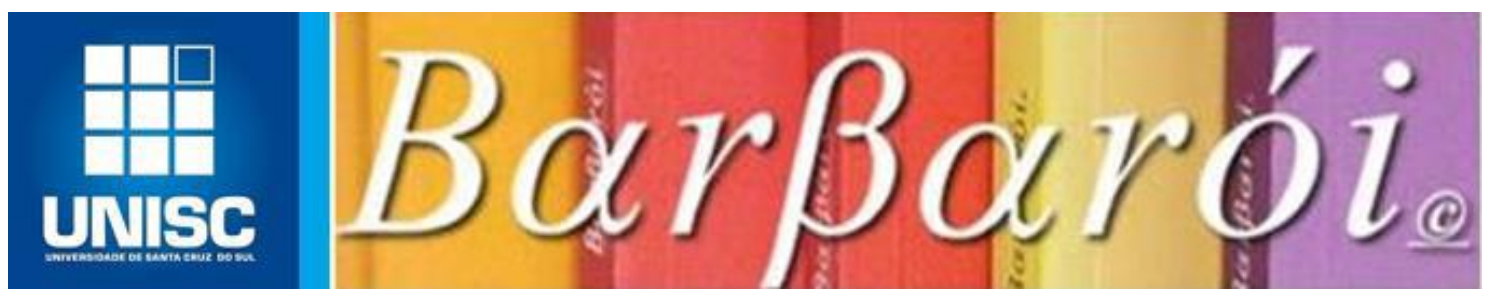

\title{
OS RESULTADOS DA HERMENÊUTICA À COMPREENSÃO DAS PESQUISAS EM EDUCAÇÃO
}

\author{
DOI: http://dx.doi.org/10.17058/barbaroi.v1i53.6566
}

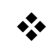 \\ Elaine Conte \\ Universidade La Salle - UNILASALLE - Brasil \\ Cristine Gabriela de Campos Flores \\ Universidade La Salle - UNILASALLE - Brasil \\ $*$
}

\begin{abstract}
Resumo
O objetivo deste trabalho é mapear as implicações metodológicas do debate hermenêutico como possibilidade compreensiva para o avanço das pesquisas em educação. O texto inicia discutindo o paradigma da modernidade e faz uma crítica às concepções tradicionais de linguagem, tendo em vista a sua incompatibilidade com algumas pesquisas das áreas das ciências humanas. Em seguida, discorre sobre as especificidades da pesquisa em educação no Brasil, tecendo interpretações sobre os fenômenos socioeducativos. Por fim, apresenta o rigor conceitual da hermenêutica que propõe questionar o sentido das teorias e ações pedagógicas no âmbito da pesquisa, a fim de (des/re)contextualizá-las às práticas educativas. As principais contribuições da hermenêutica para o campo da educação revelam uma sensibilidade para o olhar e a fala do outro, cujas expressões das relações culturais são constituintes da necessidade de ensinar a compreensão da própria sociedade que engloba as experiências pedagógicas de provocar a reflexão e a compreensão dos conteúdos textuais, buscando os sentidos das razões objetivas, subjetivas e sociais que brotam nas entrelinhas da linguagem pedagógica. Seguindo pelas trilhas da hermenêutica, aprendemos e ensinamos que na racionalidade pedagógica não lidamos com a compreensão dos objetos, nem com a compreensão da totalidade dos objetos, mas com o todo do nosso compreender humano em sua globalidade.
\end{abstract}

Palavras-chave: hermenêutica; pesquisa em educação; compreensão.

\section{Reflexões iniciais sobre o diálogo hermenêutico na educação}

Ser que pode ser compreendido é linguagem (Hans-Georg Gadamer - 1900-2002)

Quando falamos em método, geralmente pensamos em uma espécie de receita de bolo, um modelo com regras rígidas que, se forem seguidas com exatidão e de forma padronizada, levará aos objetivos almejados e ao rigor da investigação. Essa crença tem origem no modelo Barbarói, Santa Cruz do Sul, n.53, p.<67-88>,jan./jun. 2019 
das ciências naturais e exatas que foi apresentado na modernidade, como o único caminho possível para se fazer ciência e se chegar à verdade dos fenômenos investigados, tendo a precisão (empírico-indutiva e estatística) e a neutralidade como exigências ao labor científico. Atualmente, o conceito de método está sendo ampliado e colocado em xeque enquanto paradigma, pois se compreende que não existe apenas uma forma de se chegar ao conhecimento, muito menos a pretensa neutralidade do pesquisador como garantia de cientificidade. Crer na autonomia dos fenômenos sociais em relação ao próprio ser humano, ou seja, na diferenciação maniqueísta do fenômeno entre o sujeito da pesquisa e o objeto (fenômeno educativo, sociedade) a ser pesquisado acaba gerando a adesão funcionalista ao princípio da especialização radicalmente desconectada da dinâmica da vida social e da complexidade do fenômeno educativo (que só se realizam com nós linguísticos).

Conforme Gadamer (2005), ler um texto hermeneuticamente ${ }^{1}$ é considerar a experiência de choque (ou estranhamento) que ele nos causa, percebendo as diferenças no uso da linguagem e as localizando historicamente, de modo que os preconceitos sejam vistos, desconstruídos e/ou reconfigurados em um outro contexto. No caso das pesquisas no campo da educação, torna-se fundamental questionar, por exemplo, em que sentido as teorias e ações pedagógicas no âmbito da investigação foram (des/re)contextualizadas às práticas educativas? Ou até que ponto as pesquisas estão alienadas de sua própria práxis social? O método pode ser pensado como o caminho que o pesquisador irá percorrer durante o processo da pesquisa, no caso da educação como fenômeno plural, multidimensional e dialético, observando todas as dimensões humanas e outras fontes evidenciadas, de modo a compor análises mais densas para compreender os sentidos das ações investigativas e, por isso, carrega um toque de pessoalidade, por meio de uma ontologia da ação em suas múltiplas diferenças. Dito isso, quando escrevemos uma pesquisa, escrevemos para o outro, por isso ela carrega o sentido de quem a escreveu e para quem está lendo (o outro qualificado). Ao pesquisar também contribuímos para novas interpretações e construções de significado, afinal, ao interpretar e ser interpretado estamos interpretando o mundo e em transformação, nós melhoramos a nós mesmos no conflito dialógico das (re)interpretações. Para Gadamer (2005), a atitude hermenêutica é, antes de tudo, palavra, acentuando o diálogo como algo vivo e que provoca transformações no mundo. Isso quer dizer que quem deseja compreender algo não consegue se blindar da realidade e das próprias percepções.

\footnotetext{
${ }^{1}$ A hermenêutica traz presente a tradição cultural, é a arte de compreender e traduzir de maneira clara signos inicialmente obscuros, o que pressupõe entregar-se ao texto, ao outro, ao diálogo na busca do sentido da ação no mundo, como um trabalho de autocompreensão e entendimento vital.
}

Barbarói, Santa Cruz do Sul, n.53, p.<67-88>,jan./jun. 2019 
Estudos de revisão das pesquisas em educação no Brasil (GATTI, 1999; ANDRÉ, 2001) indicaram algumas fragilidades no que diz respeito às teorias e abordagens metodológicas, entre elas: a apropriação inadequada de teorias e tradições epistemológicas de outras áreas de conhecimento; uso mecânico das técnicas e instrumentos; trabalhos meramente descritivos, sem posicionamento crítico; recortes excessivamente limitados e com tendências a um pragmatismo imediatista. $\mathrm{Na}$ análise das autoras, as questões metodológicas e teóricas ainda necessitam de aprofundamento epistemológico que pode ser traduzido, na hipótese aqui apresentada, pela historicidade do debate hermenêutico. Há uma urgência por mudança, principalmente, na postura dos pesquisadores que precisam assumir uma atitude mais crítica e reflexiva em relação a todo processo de desenvolvimento da pesquisa, superando a tendência em rejeitar a percepção dialética da realidade.

Devechi e Trevisan (2010, p. 200) também "propõe uma discussão sobre a forma de recepção das pesquisas qualitativas na educação", afirmando que há uma falta de compreensão no contexto educativo acerca da rigorosidade científica o que acaba justificando as metodologias sob uma racionalidade instrumental. Os autores recuperam a dimensão do agir comunicativo da obra de Habermas (1994), para criticar o cientificismo e o positivismo presentes na racionalidade pedagógica orientada para fins estratégicos e de ação individuais, tendo em vista a força racionalmente motivadora de realizações hermenêuticas que busca o entendimento produzido por meio da coordenação de ações comunicativas no mundo (acordos produzidos na pluralidade das interpretações). De acordo com Devechi e Trevisan (2010), as pesquisas no campo educacional são criticadas porque tem mostrado carência de cientificidade e empobrecimento por falta de rigorosidade na pesquisa qualitativa devido a interpretações imediatistas, particulares e superficiais. Nesse contexto, segundo os autores, há um déficit cognitivo de compreensão e de racionalidade que resulta de uma incompreensão ou descomprometimento com a historicidade da pesquisa investigada.

Corrobora com essa discussão o trabalho de Altmicks (2014, p. 385), que visa identificar os "principais eixos paradigmáticos utilizados na pesquisa brasileira em Educação, especificamente considerando as suas implicações metodológicas". O autor traça os seis principais eixos paradigmáticos no campo da educação, a saber: 1- Positivista (Comte, métodos e técnicas objetivos de uma linguagem científica única para estudar os comportamentos humanos em sociedade, física social); 2 - Fenomenológico ${ }^{2}$ (Husserl); 3 ${ }^{2} \mathrm{O}$ termo Fenomenologia é utilizado pela primeira vez na obra Novo Organon (1764), de Johann Heinrich
Lambert, entendendo-o como uma teoria da Ilusão, porque a aparência pode: a) revelar ou apontar o caminho
rumo à verdade; b) iludir encobrindo-a ou, ainda, c) ocultar a verdade. O fundador da fenomenologia, Edmund Barbarói, Santa Cruz do Sul, n.53, p.<67-88>,jan./jun. 2019 
Marxista (Marx e Engels); 4 - Estruturalista (Saussure, Lévi-Strauss, Vygotsky e Piaget - “o estruturalismo não impõe qualquer análise histórica ou ideológica dos seus objetos" (ALTMICKS, 2014, p. 392), mas visa desconstruir e esmiuçar os fenômenos para relacionálos ao sistema onde está inserido; 5 - Funcionalista (Parsons e Mertron, função se refere ao conjunto de atividades por onde a vida social se manifesta e se estabelece); 6 - Complexidade (Morin). Para Altmicks (2014, p. 386), a ideia de paradigma foi amplamente aceita na educação por "designar o conjunto de valores, concepções, procedimentos e modelos epistemológicos compartilhados por cientistas postos sob a égide de uma mesma escola teórica". Entretanto, o termo é usado em dois sentidos diferentes, um deles, no sentido mais objetivo e homogêneo, de modelo metodológico-epistemológico, outro indicando uma tendência contingencial marcada por valores e técnicas culturais partilhados e ressignificados pela comunidade. Diante disso, é possível integrar o horizonte da crítica marcada por valores e implementada reflexivamente a partir das implicações compreensivas da hermenêutica como um nível contingente de influências e condições históricas na educação?

Não há dúvidas de que a hermenêutica tenha propriedades reflexivas na prática pedagógica. Por isso, realizamos uma reflexão hermenêutica sobre os caminhos das pesquisas em educação no Brasil como um projeto dinâmico do conhecimento e fonte de enriquecimento com o mundo, passando pela interdependência humana e linguística, fundamental para a compreensão. A hermenêutica apresenta-se como uma abordagem metodológica que busca os sentidos presentes na linguagem e nos seus limites compreensivos, com base na atitude de revisão dos problemas e contradições próprios dos textos e das experiências linguísticas com o mundo, algo fecundo em uma investigação. Dessa forma, o pesquisador que se dedica a uma atitude hermenêutica mantem vivo o pensamento questionador, contraditório, o diálogo aberto e (auto)crítico no projetar-se da investigação.

O texto proposto gira em torno de renovar a discussão de que existe um ponto vital que não é abordado pelo ensino, preso, muitas vezes, à pedagogização e às abstrações dos textos, que é a compreensão humana. A hermenêutica consiste em uma perspectiva compreensiva voltada aos textos em seus contextos e culturas plurais, de múltiplas linguagens e diferenças, ou seja, é a arte da compreensão que visa o autoesclarecimento do próprio agir no mundo. É em favor da abertura ao diálogo com a experiência do agir pedagógico, que elaboramos esse estudo, para dar visibilidade à questão do contexto e da historicidade como

Gustav Albrecht Husserl (1859-1938) agrega a palavra Ontologia - o ramo da Filosofia que se propõe a estudar a ciência do Ser como uma disciplina distinta. Toma como ponto de partida da ciência o mundo vivido, o mundo da experiência enquanto sentido da vida.

Barbarói, Santa Cruz do Sul, n.53, p.<67-88>,jan./jun. 2019 
exigência para penetrar nos processos educativos e no horizonte compreensivo da realidade contemporânea. Por tudo isso, "a hermenêutica parte do pressuposto que toma como ponto de partida a impossibilidade de o sujeito conhecedor colocar-se fora desse seu contexto querendo distanciar-se dele, a fim de dominá-lo”. (FLICKINGER, 2010, p. 157).

Existem problemáticas que acompanham o ser humano, como é o caso da racionalidade, historicidade e linguagem, que serão discutidas a seguir, tendo em vista o paradigma da modernidade e sua incompatibilidade com algumas pesquisas em ciências humanas e sociais. Em seguida, discorremos sobre as especificidades da pesquisa em educação no Brasil. Por fim, apresentamos os principais conceitos à reflexão hermenêutica no campo pedagógico.

\section{O paradigma da ciência moderna e as ciências humanas}

A ciência opera através de paradigmas (modelos, exemplos ou referencial) e tendências que comumente visam segmentar, classificar e hierarquizar os fenômenos educacionais, usando como referência um padrão metódico, ético ou cognitivo considerado científico, sem que sejam estabelecidas conexões entre as partes que compõem o fenômeno (KUHN, 1998). O ideal de um método científico baseado na comunhão com a natureza aplica o modelo da comunicação humana a um domínio onde apenas são possíveis relações instrumentais. Paradigma é uma estrutura de pensamento e de ação, trata-se de um conjunto de crenças e pressupostos teóricos compartilhados pela comunidade científica e representa a “fonte de métodos, áreas problemáticas e padrões de solução". (KUHN, 1998, p. 137). O paradigma não influencia apenas as regras de como se faz ciência, mas também a forma como a humanidade vê e interpreta o mundo. Pode-se pensar no paradigma como as lentes de um óculos que permite à humanidade focar em determinados aspectos que, naquele momento histórico, parecem mais relevantes. Na crença de que a rigorosidade científica deve abarcar apenas a constatação de fatos e a aplicação de fórmulas comprovadas, para se proteger da superstição e dos vínculos com o senso comum, a rigorosidade metódica expulsa o pensamento complexo e ratifica a objetificação e os modismos da pesquisa operada na produção acadêmica.

Thomas Kuhn defende que a ciência não evolui de forma histórica, cumulativa e linear, mas sim, através de revoluções, isto é, pela substituição de um paradigma por outro. É necessário uma ruptura com o paradigma da ciência normal para que outro possa emergir. E quando isso acontece? A mudança de paradigmas é um processo lento e gradual, que pode ter início quando os problemas científicos não podem ser explicados através do paradigma da Barbarói, Santa Cruz do Sul, n.53, p.<67-88>, jan./jun. 2019 
ciência normal e após as tentativas frustradas da comunidade científica de encaixar as descobertas em pressupostos já existentes, instala-se um sentimento de fracasso e insegurança. Para Kuhn (1998, p. 95), “a emergência de novas teorias é geralmente precedida por um período de insegurança profissional pronunciada, pois exige a destruição em larga escala de paradigmas e grandes alterações nos problemas e técnicas da ciência normal". Assim, o autor caracteriza a crise como esse período transitório entre a não eficácia do paradigma da ciência normal e a não existência de um novo paradigma (substituto). Na perspectiva de Altmicks (2014, p. 387),

\begin{abstract}
A pesquisa educacional brasileira foi fundada, nos anos 40, sob a égide do Positivismo. Pretendia-se neutra e, portanto, não disponibilizava espaço para a práxis na consecução das suas investigações. Incapaz de propor soluções efetivas aos problemas educacionais do país, o Paradigma Positivista foi substituído, na década de 1970, pelo de matriz fenomenológica.
\end{abstract}

A fenomenologia de Husserl propôs descrever o fenômeno (epocké - descrição da natureza do fenômeno, buscar a sua essência, a parte mais invariável da experiência no contexto), e não explicá-lo ou buscar relações causais, voltando-se para as coisas mesmas como elas se manifestam. A concepção de Husserl busca reintegrar o mundo da ciência ao mundo da vida voltando ao mundo da experiência, antes da realidade objetiva, considerando que há um sujeito que a vivencia. No princípio subsequente, surge a crítica ao paradigma fenomenológico visto que ele comportava a intencionalidade da subjetividade humana à pesquisa imediata, de modo academicista, justamente por incluir a percepção dos sujeitos frente à investigação do fenômeno, mas, contraditoriamente, se predispunha a não intervenção metodológica na realidade pesquisada e a desconsiderar a historicidade do objeto investigado.

Para suprir esta lacuna, uma década depois, veio o marxismo e propôs o seu materialismo histórico dialético, cuja ênfase na práxis e na intervenção social tornava-o quase perfeito para as investigações educacionais. A estrutura de uma investigação científica marxista parte da realidade concreta e é enunciada pelos seguintes procedimentos: 1) vivência da realidade que se pretende investigar; 2) análise crítica desta realidade, de modo a compreendê-la nas suas sínteses dialéticas; 3 ) interferência, no sentido de sanar os problemas (ALTMICKS, 2014). Em outras palavras, podemos dizer que inicia pela observação dos fenômenos para pensar, a partir dele, os conflitos dos dados reais e as relações entre os mesmos, enxergando-os como sínteses históricas de muitas outras relações socioeconômicas (anteriores e determinantes), constituindo reflexos da própria materialidade em movimento no pensar dialético-histórico. Ainda que o marxismo tenha sido dominante na pesquisa em educação, em meados dos anos 90, um breve flerte com o Estruturalismo e o Funcionalismo. 
No final da década, surge uma nova perspectiva epistemológica, ligada às teorias da Complexidade, que ainda não se consolidou como paradigma. "Diferente da dialética marxista, que segmenta os momentos de tese, antítese e síntese, Morin acredita que tais elementos estão imbricados e em aleatória mudança”. (ALTMICKS, 2014, p. 397).

Para Boaventura de Souza Santos (2009), vivemos em um período de crise. Ele percebe o momento atual como de perplexidade e desconfiança epistemológica. $\mathrm{O}$ conhecimento ultrapassou os limites do paradigma da modernidade dominante e caminha em direção a outro: o paradigma emergente. Para Habermas (1994), vivemos no paradigma moderno, cujo projeto de esclarecimento ficou inacabado, por isso, precisamos manter em aberto as diferentes perspectivas reconstrutivas do diálogo hermenêutico, enquanto observadores e participantes num fenômeno educativo e social que é atravessado, do princípio ao fim, pela questão do outro. Essa abordagem é retomada por Devechi e Trevisan (2010, p. 155-156), nos seguintes termos:

\begin{abstract}
A diferença entre uma abordagem qualitativa e outra está na posição do sujeito e na compreensão do objeto. Para a abordagem fenomenológico-hermenêutica, o sujeito está no centro da relação sujeito-objeto, ou seja, ela propõe uma redescoberta do sujeito diante da ilusão da objetividade preconizada pelo positivismo, sendo o objeto uma qualificação do processo de interpretação. Para as abordagens crítico-dialéticas, não existe centralização, o sujeito e o objeto possuem o mesmo peso de importância para o conhecimento, sendo o objeto um elemento ontológico. Já para as abordagens hermenêutico-reconstrutivas, a centralização está nas relações entre os sujeitos (sujeito-sujeito), sendo o objeto uma suposição acordada sobre o mundo objetivo.
\end{abstract}

A ciência moderna rompeu com o paradigma que a precedeu, o saber aristotélico e medieval, através do modelo de racionalidade e nele pautou seus princípios epistemológicos e regras metodológicas. Os protagonistas do paradigma da modernidade lutaram contra toda forma de dogmatismo e autoridade. Descartes, o precursor do paradigma da modernidade, elaborou um método capaz de produzir e julgar o conhecimento e acreditava que por meio das etapas e normas do método o cientista chegaria à verdade. Contudo, a partir do raciocínio de Najmanovich (2003), os seguidores do método criado por Descartes divulgaram o conhecimento resultante de suas pesquisas ocultando todos os erros e dificuldades que aconteceram durante o processo e, somente por isso, puderam apresentar o caminho ao conhecimento como "um traçado direto, sem rodeios, que nos conduz em uma linha reta desde a ignorância ao saber guiado somente pelas suas normas”. (NAJMANOVICH, 2003, p. 29).

No paradigma da modernidade, a matemática recebeu lugar central, defendia-se que somente com a lógica das ciências exatas seria possível a análise, a investigação e a 
representação das estruturas da matéria. Nessa perspectiva, o que não pode ser quantificado não pode ser conhecido, sendo assim irrelevante estudar. Para a ciência moderna, "o mundo é complicado demais e a mente humana não o pode compreender completamente. Conhecer significa dividir e classificar para depois poder determinar relações sistemáticas entre o que separou". (SANTOS, 2009, p. 28). Por esses motivos, Boaventura identifica o modelo de racionalidade como um modelo totalitário, pois apenas considera racional e, portanto, científico e verdadeiro, o conhecimento produzido através de seus próprios princípios e regras metodológicas. Boaventura define o conhecimento científico desse paradigma como "um conhecimento causal que aspira à formulação de leis, à luz de regularidades observadas, com vista a prever o comportamento futuro dos fenômenos". (SANTOS, 2009, p. 29). As leis de Newton são um exemplo do conhecimento considerado verdadeiro e científico pelo paradigma dominante.

Nesse contexto, a ciência da natureza passa a ser considerada como uma ciência superior, verdadeira porque é passível de verificação e quantificação matemática. Em contrapartida, o conhecimento humano (subjetivo), sensível e social surge como não racional ou não científico, suprimindo-se do discurso sobre a ciência o senso comum e os estudos humanísticos. E essa foi uma das heranças que o paradigma da modernidade nos deixou: a desvalorização das chamadas ciências sociais e humanas. Desde então as ciências humanas vêm buscando se encaixar na racionalidade mensurada e objetiva das ciências exatas. No entanto, Hermann (2002, p. 20) diz que "a forma de conhecer das ciências da natureza não é senão uma das formas de conhecer, não sendo legítima sua transposição para as ciências humanas". Diante disso, "as abordagens qualitativas têm importância para a educação na medida em que mostram a insuficiência das abordagens quantitativas no sentido puro e que o domínio do objeto é, desde sempre, dependente da incorporação da subjetividade ou do acordo intersubjetivo, sendo esses elementos historicamente modificáveis". (DEVECHI; TREVISAN, 2010, p. 159). Cabe aqui destacar que a historicidade da hermenêutica revela diferentes interpretações do conceito.

Hans-Georg Gadamer (1900-2002) é o principal responsável por nosso pensamento sobre a hermenêutica na filosofia contemporânea hoje por três motivos. Primeiro, Heidegger abandonou o termo em seus últimos escritos. Segundo, Sartre, que defendeu o existencialismo, que foi parcialmente defendido a partir de Ser e tempo de Heidegger, não incorporou a hermenêutica. Terceiro, Gadamer, um aluno de Heidegger, desenvolve especificamente a análise da compreensão de Heidegger de Ser e tempo em sua obra principal, Verdade e método, chamando sua teoria de hermenêutica filosófica (SCHMIDT, 2014, p. 21; grifos da autora). 
É nesse contexto que se encontram as pesquisas e os novos percursos em educação no Brasil, conforme ilustramos no Quadro 1 e Quadro 2, a seguir.

Quadro 1 - Perspectivas hermenêuticas em educação

\begin{tabular}{|l|l|l|}
\hline $\begin{array}{l}\text { FENOMENOLÓGICO- } \\
\text { HERMENÊUTICAS }\end{array}$ & CRÍTICO-DIALÉTICAS & $\begin{array}{l}\text { HERMENÊUTICO- } \\
\text { RECONSTRUTIVISTAS }\end{array}$ \\
\hline $\begin{array}{l}\text { Hans-Georg Gadamer } \\
\text { Filósofo alemão }\end{array}$ & \multicolumn{1}{|c|}{$\begin{array}{c}\text { Karl Marx } \\
\text { Filósofo, sociólogo, } \\
\text { jornalista e revolucionário }\end{array}$} & $\begin{array}{l}\text { Karl-Otto Apel } \\
\text { Filósofo alemão }\end{array}$ \\
\hline $\begin{array}{l}\text { Edmund Husserl } \\
\text { Matemático e filósofo } \\
\text { alemão }\end{array}$ & $\begin{array}{l}\text { György Lukács } \\
\text { Filósofo húngaro }\end{array}$ & $\begin{array}{l}\text { Jürgen Habermas } \\
\text { Filósofo e sociólogo alemão }\end{array}$ \\
\hline $\begin{array}{l}\text { Martin Heidegger } \\
\text { Filósofo alemão }\end{array}$ & $\begin{array}{l}\text { Antonio Gramsci } \\
\text { Filósofo italiano, jornalista, } \\
\text { crítico literário e político }\end{array}$ & $\begin{array}{l}\text { Axel Honneth } \\
\text { Filósofo e sociólogo alemão }\end{array}$ \\
\hline
\end{tabular}

Fonte: Elaboração própria, com base em Devechi e Trevisan (2010).

Quadro 2-Características das abordagens

FENOMENOLÓGICO-
HERMENÊUTICAS

Sujeito: centro da relação surge como intérprete do objeto.

Mundo: Compreensão a partir do momento histórico e da experiência humana no mundo.

Pesquisa: desvendar/decodificar o sentido do contexto (implícito e subjetivo).

\section{CRÍTICO-DIALÉTICAS

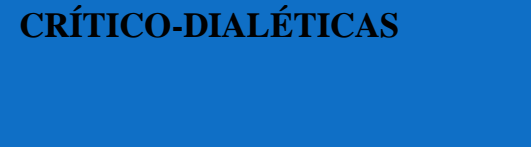

Sujeito (descentrado) como um elemento dinâmico que se contrapõe ao objeto e vice-versa, que age a partir das condições que o rodeiam.

Mundo: interesses antagônicos e em construção.

Pesquisa: caráter conflitivo, manifestada no interesse transformador da realidade.

\section{HERMENÊUTICO- RECONSTRUTIVISTAS}

Sujeito (descentrado) e justificado na relação com o outro e no agir comunicativo voltado ao consenso.

Mundo: processo de reflexão crítica e validação das abordagens.

Pesquisa: descentramento do sujeito, considera as forças sociais, econômicas e a evolução do cenário. O outro é a categoria central das pesquisas e tais investigações surgem como reação à hermenêutica tradicional que havia subsumido o outro na tradição.

Técnica: não está formatada porque ainda necessita se consolidar. O que muda: tratamento dos dados quanto à validação diante do outro e do todo.
Técnicas: questionário, entrevista, narração, história de vida, pesquisa participante e etnográfica e pesquisa-ação. etnografia, pesquisa participante e pesquisa-ação.

Fonte: Elaboração própria, com base em Gamboa (2008) e Devechi; Trevisan (2010). 
A educação é uma área de conhecimento que está diretamente relacionada com a ação das pessoas, além disso, apresenta demandas que o método da ciência moderna por si só não foi capaz de atender, a saber, a especificidade do humano enquanto inclusão das dimensões subjetiva, objetiva e social. Tudo indica que o esforço investigativo exige levar em consideração as diferentes linguagens, percepções, interpretações, sujeitos, observações, contextos e mundos constituídos e em construção à condução de uma práxis hermenêutica complexa da educação.

\section{A especificidade da pesquisa em educação}

A palavra pesquisa, nesse trabalho, implica reconhecer que não se pode apreender a totalidade de um fenômeno educativo de maneira absoluta e exata, visto que os fenômenos da experiência humana são fontes inesgotáveis de investigação e (re)interpretações. Como abertura para o novo, o ato de compreender hermenêutico sempre alcança toda a constituição quando está vinculado ao agir no mundo. Pesquisas e estudos científicos comprometidos com a validade, o rigor e a consistência de suas descobertas e que utilizam de métodos para buscar "uma compreensão que ultrapasse nosso entendimento imediato, elaborando um conhecimento que desvende processos obscuros, subjacentes, um conhecimento que lance luz sobre fenômenos, sobre uma questão, segundo algum referencial". (GATTI, 2006, p. 26). Nessa perspectiva, o método é, então, o meio pelo qual o pesquisador produz o conhecimento ou ainda, em outras palavras, o caminho percorrido pelo pesquisador durante seu estudo. $\mathrm{O}$ grande problema da humanidade é que todos nós somos idênticos e diferentes, e precisamos lidar com essas duas ideias que não são compatíveis (MORIN, 2018, online).

\footnotetext{
Pensar a educação na perspectiva ética da alteridade é compreender que as racionalidades são frágeis na forma de conceber o olhar educativo para o outro, pois, muitas vezes, a alteridade é tomada na educação sob a perspectiva da instrumentalização técnica e da objetificação do conhecimento. A formação só passa a ter sentido humano quando está alicerçada na relação de interdependência sensível e de abertura aos valores e comportamentos diferentes. (HABOWSKI; CONTE; PUGENS, 2018, p. 195).
}

Gadamer e Almeida (2000) defendem que é na experiência do encontro com o outro que emana a possibilidade de compreensão intersubjetiva e a capacidade de realizar experiências socioculturais carregadas de sentido, reflexões e conversações, expondo-se, com isso, ao inesperado, ao imprevisível da experiência formativa e educativa. "Na hermenêutica filosófica, o diálogo é pensado como elemento constituinte do ser humano que se concretiza 
plenamente pela interdependência linguística com o outro". (HABOWSKI; CONTE; PUGENS, 2018, p. 181).

$\mathrm{Na}$ fase atual do desenvolvimento da pesquisa educativa, que se caracteriza pela profusão de abordagens teórico-metodológicas, de onde as possibilidades de opções epistemológicas são muitas, é urgente a elucidação dos pressupostos de cada abordagem, a busca de seus fundamentos epistemológicos e filosóficos e maior a responsabilidade por esclarecer as correspondentes implicações sociais e políticas de cada opção. De igual maneira, é premente a necessidade de reflexões sobre as atitudes e posturas éticas do pesquisador em educação. (GAMBOA, 2008, p. 182).

Como mencionado anteriormente, o paradigma da modernidade apresentou o método de Descartes como o único caminho para se chegar ao conhecimento. Atualmente, a comunidade científica ampliou a compreensão acerca de método, para Gatti (1999, p. 63), "método é ato vivo, concreto, que se revela nas ações, na nossa organização e no desenvolvimento do trabalho de pesquisa, na maneira como olhamos as coisas no mundo". Dessa forma, sem abrir mão do rigor conceitual e argumentativo, é possível pensar outras modelos e abordagens de produção de conhecimento, para além do método de Descartes.

De acordo com Gatti (1999), a área da educação caracteriza-se por ser uma área de conhecimento de ação-intervenção direta e, por isso, a pesquisa deve buscar o conhecimento que diz respeito "à relação/incorporação de teorias com/em práticas intencionais, com finalidades socialmente definidas”. (GATTI, 1999, p. 66). Nesses processos de produção de conhecimentos, "a reflexão, o estudo, a investigação sobre seus modos de intervir é que constituem sua área privilegiada de construção de conhecimento". (GATTI, 1999, p. 66). Diante dessa compreensão sobre a especificidade da pesquisa em educação, justifica-se a importância da reflexão acerca das abordagens, dos métodos e das teorias para corresponder as demandas das temáticas desse campo de conhecimento, superando a tendência à instrumentalização e abstração metódica. Para Gatti (1999, p. 72),

\footnotetext{
O método nasce do embate de ideias, perspectivas e teorias com a prática. Ele não é somente um conjunto de regras que ditam um caminho. É também um conjunto de crenças, valores e atitudes. Há que se considerar o aspecto interiorizado do método, seu lado intersubjetivo e até, em parte, personalizado pelas mediações do investigador. Ou seja, o método, para além da lógica, é a vivência do próprio pesquisador com o pesquisado.
}

Ao avaliar a história da pesquisa em educação no Brasil, Gatti (1999) tece uma crítica sobre a falta de profundidade e a utilização mecânica e ritualística dos métodos de investigação. Segundo a autora, "saímos de uma forma de coleta de dados para outra e não percebemos que os problemas de fundo são os mesmos, e que qualitativo em pesquisa não é dispensa de rigor e consistência”. (GATTI, 1999, p. 70). Assim, para a referida autora, o 
principal desafio das pesquisas em educação não consiste em encontrar novos instrumentos ou procedimentos metodológicos, mas sim avançar em busca de novas atitudes e perspectivas, abrir espaço para a reflexão e (inter)subjetividade, valorizando o lugar do pesquisador enquanto produtor de conhecimento. No entanto,

[...] a má condução das pesquisas qualitativas na educação aparece como um dos fatores predominantes, os quais a têm transformado por vezes mais num palco de lutas autodestrutivas do que propriamente num ambiente de saudável convívio democrático. [...] esse modelo investigativo estaria demonstrando dificuldades em ir além daquilo que seria uma mera investigação imediatista da realidade, tornando-se mais descritora do óbvio do que investigadora científica. (DEVECHI; TREVISAN, 2010, p. 149).

Dessa forma, não basta apenas procurar um novo método ou usar a bricolagem metodológica e sim mudar a relação dos investigadores com a pesquisa, sua abordagem e postura diante da temática, trazendo as inter-relações e tensões entre o local e o global. Nesse sentido, a reflexão hermenêutica pode ser pensada como uma possível alternativa, já que essa abordagem apresenta-se como uma racionalidade para compreender e interpretar seu objeto de estudo no mundo. Os fundamentos da reflexão hermenêutica como aplicação real e compreensiva de atitudes racionais precisam ser recontextualizados no campo da educação pela mediação linguística e pela sensibilidade humana, a fim de serem usados, de fato, no mundo da vida, para além dos particularismos, e reconhecidos na globalidade social e singularidade expressiva (da imaginação criadora).

Frente a isso, Edgar Morin (2000) diz que não compatibilizamos a preocupação com a transmissão e assimilação de conteúdos numa época de grande complexidade de informações e, por isso, não conseguimos ensinar a compreensão das condições de um conhecimento que não mutila o seu saber, tornando-o prisioneiro das próprias conceituações fechadas da cultura especializada da particularidade. No horizonte da discussão, está a hipótese de que é preciso ter uma visão que possa estudar a incompreensão (o racismo, a xenofobia, os dogmatismos e maniqueísmos) dos diversos discursos vigentes na educação, no sentido de auxiliar pedagogicamente o aspecto conceitual da cultura, mas também refletir a dialética da cultura em suas relações junto ao processo educativo, para que esse processo pedagógico possa voltar a ter sentido e tocar o mundo da vida. Ou seja, tudo isso implica a capacidade do professor de colocar em movimento o conhecimento no contexto local e global (MORAN, 2000; 2018). A crise na educação e nos processos de ensino surge por conta da ausência desses momentos interpretativos e compreensivos dos contextos e das (con) tradições humanas, em que os professores precisam dialogar com os outros saberes e com os estudantes, visto que essa 
produção do saber partilhado e mais comprometido com a reflexão ainda não aconteceu. Em termos pragmáticos, a compreensão hermenêutica na educação acontece,

\begin{abstract}
Por exemplo, quando um professor passa uma lição a um aluno, que vai buscar uma resposta na Internet, ele deve posteriormente corrigir os erros cometidos, criticar o conteúdo pesquisado. [...] O conhecimento complexo evita o erro, que é cometido, por exemplo, quando um aluno escolhe mal a sua carreira. Por isso eu digo que a educação precisa fornecer subsídios ao ser humano, que precisa lutar contra o erro e a ilusão. (MORIN, 2018, online).
\end{abstract}

Diante dessas constatações, Edgar Morin (2018, online) questiona: “É possível sairmos de uma visão fechada em formas particulares para o pensamento complexo, capaz de ver os problemas em sua integralidade?". Para compreender um texto, por exemplo, precisamos ir além da decifração dos signos, por meio do dicionário ou da gramática, pois o texto carrega uma função e um horizonte social que precisa ser levado em consideração para reconstruir o mundo de possibilidades do autor e dos intérpretes dos conteúdos apreendidos, a partir da totalidade do contexto. Isso porque, as palavras englobam o processo interpretativo que não tem significado fixo e unívoco no texto em si, independentemente das formas de uso e dos contextos de aplicação. A partir de inter-relações que constituem o mundo podemos ressignificar as palavras e os aspectos que afetam a comunicação, criando novas expressões para dizer o que não se deixava dizer.

\title{
Racionalidade e justificação da circularidade da investigação hermenêutica
}

De acordo com Hermann (2002), a hermenêutica propõe uma outra forma de acessar o conhecimento em oposição ao modelo único, proposto pela ciência moderna, uma vez que, seu "fundamento da verdade não está nos dados empíricos nem na verdade absoluta; antes é uma racionalidade que conduz a verdade pelas condições humanas do discurso e da linguagem”. (HERMANN, 2002, p. 20). A linguagem é o elemento fundamental da reflexão hermenêutica. Stein (2004) afirma que é através da linguagem que o ser humano se relaciona com o mundo e é por meio dela que se dá todo o saber. De acordo as palavras do autor, "o ser humano somente é racional porque seu acesso ao mundo se dá via sentido, via significado, via conceitos, via palavras, via linguagem". (STEIN, 2004, p. 17). Portanto, pode-se inferir que a hermenêutica é uma forma de linguagem que permite ao ser humano chegar ao objeto pelos diversos usos e formas de linguagem, além disso, a hermenêutica é o caminho alternativo à produção e reconstrução do conhecimento, cuja obra e o obrar-se humano exige ensinar a compreensão, os significados, a partir do ato de compreender e interpretar os sentidos da ação expressos na linguagem. 
Martin Heidegger (1889 - 1976) é considerado um dos filósofos mais importantes do século XX. Em sua obra clássica Ser e Tempo, Heidegger relaciona a reflexão da hermenêutica filosófica à compreensão e interpretação do sentido do ser. Nesse ponto, percebemos que "a compreensão é menos um conhecimento do que um inserir-se no mundo". (HERMANN, 2002, p. 37). Ou seja, compreender não é apenas uma atividade do ser humano, mas sim o modo de ser-no-mundo.

\begin{abstract}
Esse giro investigativo não funciona sem o componente da resistência, sem o contraditório, ou aquilo que o nega (diferença). Daí que surge o estranhamento hermenêutico e a necessidade de mudar, de ultrapassar os obstáculos conservadores para compreender o pensamento da humanidade na conversação, pois o visível tem sempre aspectos de invisibilidade. (SIDI; CONTE, 2018, p. 1946).
\end{abstract}

Diferentemente do pensamento moderno, onde se busca a separação entre sujeito e objeto, a hermenêutica compreende que o sujeito não está isolado do mundo nos procedimentos de pesquisa, mas comunica-se com o outro, com a natureza e com o mundo durante o processo de compreensão e (re)interpretação descentrada. Além disso, no pensamento heideggeriano, a compreensão acontece em uma estrutura circular que abrange os conceitos de pré-compreensãao ${ }^{3}$ e de consciência histórica (posição e historicidade humana de sua imersão em determinada tradição). Gadamer (2005, p. 18) diz que "a consciência histórica já não escuta beatificamente a voz que lhe chega do passado, mas, ao refletir sobre a mesma, recoloca-a no contexto em que ela se originou, a fim de ver o significado e o valor relativo que lhes são próprios”.

Para Gadamer (2005), o pesquisador deve iniciar seu processo de investigação questionando-se e refletindo sobre suas pré-compreensões e conhecimentos teóricos a respeito da temática a ser pesquisada, visto que esse reconhecimento dá ao pesquisador a clareza de sua situação hermenêutica. Stein (2004, p. 57) define a situação hermenêutica como "lugar que cada investigador atinge, a partir do qual ele pode fazer uma investigação sistemática de determinado campo". Nesse sentido, o investigador que pretende realizar uma compreensão hermenêutica precisa estar ciente de seu pertencimento a um tempo e uma tradição, assim como seu objeto de estudo, mantendo uma postura reflexiva e (auto)crítica durante o processo. Dessa forma, a tarefa hermenêutica consiste em mediar a tensão existente entre o estranho do objeto e o familiar da tradição, durante o processo de compreensão e interpretação. Ao se relacionar com o objeto, o intérprete tem suas pré-compreensões

\footnotetext{
${ }^{3} \mathrm{O}$ conceito de pré-compreensão ou estrutura prévia da compreensão consiste no reconhecimento dos preconceitos, que atuam como uma rede de significados, que os seres humanos, enquanto seres históricos e pertencentes a uma cultura, trazem consigo e que são o ponto de partida para a projeção de sua compreensão.
}

Barbarói, Santa Cruz do Sul, n.53, p.<67-88>, jan./jun. 2019 
reelaboradas, surgindo um novo horizonte de compreensão. Trata-se de um processo dialógico, que permite que o novo venha à luz a partir da mediação do antigo, em termos de pré-compreensão, do interrogar-se, da reinterpretação atualizada e busca de sentidos para o contexto em análise. Esse processo é denominado círculo hermenêutico, pois "somos o mundo e ao mesmo tempo projetamos o mundo. Estamos envolvidos com os objetos do mundo e descrevemos o mundo no qual se dão os objetos", pela relação que estabelecemos com os outros na fusão de horizontes e ampliação da base epistemológica enquanto (des/re)construção do conhecimento (STEIN, 2004, p. 66).

O acesso aos objetos é possível através da linguagem humana e da capacidade de atribuir significados e novos sentidos diante das compreensões preexistentes no mundo. A linguagem, assim, é a forma como tudo se dá (STEIN, 2004). Tais funções exigem do pesquisador uma atitude reflexiva e vigilante, pois os instrumentos e metodologias escolhidos no início do processo de pesquisa deverão ser revisados e ajustados no desenvolvimento da obra, do projetar-se no mundo com os outros. Além disso, ao defender que a ideia de objetividade é um mito, a hermenêutica autoriza e dá legitimidade ao olhar de cada sujeito que se propõe a assumir o lugar de pesquisador. Sobre isso, Gatti (1999, p. 77) defende que "no trabalho humano, na produção humana, há esta característica do algo mais que é individual e depende do envolvimento pessoal, daquilo que se põe de si mesmo no trabalho". Essa análise da articulação entre individual e social, passado e presente, contextual e global, leva-nos a considerar a dimensão temporal da historicidade e da pluralidade cultural, em termos de representações sociais. Assim,

\footnotetext{
Não há como compreender a realidade da prática educacional sem o conhecimento de como tal prática se estrutura no seu desenvolvimento cotidiano, do mesmo modo em que, sem o amparo teórico adequado, as pesquisas empíricas podem não ser capazes de problematizar os dados coletados e, por conseguinte, de transcender a condição de simples descrição da realidade (DALBOSCO; SANTA; BARONI, 2018, p. 152).
}

Embora a hermenêutica não seja um método que se caracterize por etapas ou por conter um passo a passo rígido, Stein (2004) lista três procedimentos ou caminhos possíveis para o pesquisador em seu processo de investigação: $\mathrm{O}$ primeiro, denominado de história conceitual, trata-se do trabalho do pesquisador em articular e interligar os conceitos existentes sobre seu objeto de estudo, formando uma rede de conceitos que possibilitará uma melhor compreensão do mesmo. O segundo refere-se ao reconhecimento da tradição epistemológica. Trata-se da análise sobre o contexto da descoberta e o contexto da justificação. Isto é, em um primeiro momento, ao observar o objeto, o pesquisador dedica-se a descrevê-lo 
historicamente e analisar o sentido relacionado à atualidade, da situação em que ele se encontra. Em um segundo momento, o pesquisador volta sua atenção para o contexto da justificação, e procura uma forma lógica para compreender aquilo que observou no contexto da descoberta. Para Hermann (2003, p. 10), “assim, a possibilidade compreensiva da hermenêutica desfaz o prejudicial equívoco que há entre educação compensatória e educação no sentido amplo da formação".

Por fim, o terceiro chama-se caminho da especulação. A especulação é um elemento que traz possibilidades criativas e inventivas para o caminho da investigação, foi esse caminho que possibilitou boa parte das descobertas científicas. De acordo com Stein (2004, p. 104), "trata-se de uma capacidade de percebermos em determinado texto e de desenvolvermos pela reconstrução e interpretação do texto uma espécie de espessura no nosso discurso". E o autor conclui: "método e não-método se misturam criativamente em textos de ciências humanas. Justamente fazemos isso para poder dar conta da complexidade dos fatos sociais, dos acontecimentos históricos, dos casos na psicanálise”. (STEIN, 2004, p. 105).

Como vimos até aqui, a hermenêutica apresenta uma alternativa à crença de um caminho único e seguro de chegar ao conhecimento e também à busca por uma verdade absoluta, trazendo perspectivas de bases interpretativas, da produção de sentido e da “impossibilidade de separar o sujeito do mundo objetivado". É por esse reconhecimento e abertura à subjetividade e à sensibilidade do pesquisador que a hermenêutica pode ser pensada como um caminho (talvez) não tão seguro e previsível, mas muito mais provocativo e promissor para as pesquisas em educação no Brasil (HERMANN, 2002, p. 16). Nas palavras de Gadamer (2000, p. 23),

\footnotetext{
Compreender não é, em todo o caso, estar de acordo com o que ou quem se compreende. Tal igualdade seria utópica. Compreender significa que eu posso pensar e ponderar o que o outro pensa. Ele poderia ter razão no que diz e no que propriamente quer dizer. Compreender não é, portanto, uma dominação do que nos está à frente, do outro e, em geral, do mundo objetivo.
}

Segundo Gadamer (2006), o sentido da investigação hermenêutica está em revelar o milagre da compreensão. Compreender significa participar de uma perspectiva comum pela necessidade de reagendar o diálogo vivo e operar uma mediação entre o presente e o passado, inerente ao horizonte do contexto. Os desafios da hermenêutica na cultura plural e digital contemporânea residem em reavivar o diálogo crítico com a própria tradição cultural, resistindo ao fenômeno da incomunicação, dispersão, pulverização e redução, no sentido de gerar a problematização e a reconstrução do texto, para que, mergulhados no contexto, possamos estudar o fenômeno humano complexo, aberto e flexível, mobilizando a 
intercompreensão. Revendo equívocos das abordagens qualitativas, Devechi e Trevisan (2010, p. 157-158) lançam quatro provocações que convergem para novas investigações baseadas na intersubjetividade da compreensão e historicidade conceitual, são elas:

\begin{abstract}
1) A pesquisa qualitativa não é contrária à pesquisa quantitativa, pois não se trata de posições antagônicas, mas desiguais e complementares. [...]. 2) A crítica que se faz ao quantitativo nas pesquisas qualitativas é em relação ao uso do quantitativo puro, não à participação do quantitativo no qualitativo. [...]. 3) É necessário ter claro que a descentralização do eixo de gravidade do objeto não significa que ele deva ser abandonado, pois esse é um elemento fundamental ao entendimento do mundo. [...].

4) Reafirmamos a necessidade imprescindível de ter precisão no conhecimento dos aspectos teóricos, técnicos e metodológicos de cada abordagem.
\end{abstract}

Seguindo essa linha de raciocínio, Devechi, Tauchen e Trevisan (2012) compactuam com a ideia de que há uma relação formativa, interdependente e conflituosa entre teoria e prática, que exige uma permanente (des)problematização da realidade, cuja validade das hipóteses investigadas precisam ser reintegradas no contexto da ação vital. No confronto do saber com a prática social, "Habermas nos autoriza pensar que o saber problematizado no discurso tem maior chance de êxito na prática, tendo em vista o esgotamento do uso de uma racionalidade comunicativa em que diferentes interpretações acerca do mesmo mundo são colocadas em xeque na troca argumentativa". (DEVECHI; TAUCHEN; TREVISAN, 2012, p. $71)$.

\title{
Considerações Finais
}

Estudos apontam que as pesquisas na área da educação no Brasil apresentam fragilidades metodológicas e teóricas, bem como uma pulverização de abordagens (aplicação metódica), uma vez que falta a compreensão de que a verdade científica encontra-se imersa na dinâmica do tempo, dos processos e relações intersubjetivas, no diálogo e na possibilidade de experimentar o mundo humano de imprevisibilidades (HERMANN, 2002). Para Gatti (1999) e André (2001), os pesquisadores da área da educação precisam assumir uma postura mais crítica e reflexiva no processo de investigação e desenvolver a capacidade de compreender e interpretar as ideias dos autores, os conceitos e os resultados de suas pesquisas. Concluímos que, no cenário atual da hermenêutica na educação, precisamos não só ensinar a compreensão, mas promover a experiência da leitura de um texto em voz alta, que ganha um sentido outro que não é alcançado apenas na leitura silenciosa. A excitação da leitura promove a experiência da linguagem que exige uma nova forma de atuação pedagógica, pois a interpretação é filha de seu tempo, que passa por ouvir o outro e estimular a expressão de uma mensagem, extraindo das contradições com a melodia da linguagem o potencial semântico do 
discurso ainda distante das práticas de ensino. Mas, abrir os olhos para as incompreensões e as distorções das (des)informações que permeiam o nosso cotidiano, ensinando e aprendendo a compreensão, exige a atitude crítico-investigativa de interpretar o contexto manipulador, em que somos obrigados a viver como autômatos (exaustão humana) no mundo globalizado (HABERMAS, 1994). A arte de educar enquanto dimensão hermenêutica de sentido linguístico voltado para a interpretação ultrapassa o horizonte limitado de mundo porque tem um sentido humano e sempre ampliável de nossa linguagem.

Contudo, se faz necessário buscar caminhos que possibilitem o crescimento dos pesquisadores e da pesquisa em educação no Brasil, para que possamos avançar em rigor, consistência e qualidade, superando os modismos metodológicos. Pois, embora o paradigma da modernidade tenha apresentado o método cartesiano como o único caminho para se chegar ao conhecimento verdadeiro, sabemos que diversas temáticas das ciências humanas não podem ser pensadas através de um modelo lógico-matemático e demandam outras fontes de justificação. Sem sombra de dúvidas, o reconhecimento e a legitimidade do contexto como inerente e necessário às pesquisas educacionais surge como condição à observação e compreensão da totalidade humana da qual uma (auto)crítica poderia desenvolver-se. A tese da neutralidade metodológica é posta em xeque nesse contexto hermenêutico, pois ela não pode domesticar e controlar as aspirações do mundo social e das pesquisas sobre uma humanidade inconclusa, em termos das possibilidades de compreensão, desbloqueada pelo projetar-se humano do diálogo como um todo (HABERMAS, 1994).

De acordo com Gadamer (2005, p. 356), "quem quiser compreender um texto realiza sempre um projetar", situado no saber e na ação vital, que leva à reflexão, às dúvidas em relação à vida e que se mostra nas experiências complexas do mundo. Nesse sentido, a abordagem hermenêutica se dispõe a compreender os sentidos presentes em toda e qualquer forma de linguagem humana, sem aderir à simplificação dos recursos da linguagem em nome da linearidade do fazer científico. Além disso, sem abrir mão do rigor conceitual e argumentativo, a hermenêutica reconhece o espaço da (inter)subjetividade e da pessoalidade no caminho investigativo, visto que tal práxis educativa se constitui na relação dialética entre autonomia e interdependência social, que se retroalimentam no campo da pesquisa enquanto ato de pensar a educação, na teia de relações linguísticas e do pertencimento a realidade. A atitude hermenêutica resgata uma concepção comunicativo-normativa de intersubjetividade inerente às estruturas performativas de nossas relações educativas, vivências e práticas cotidianas, que aproxima o campo da escola ao entendimento crítico trazido pelo confronto do 
concreto e pela inter-relação da historicidade da compreensão, presente na tradição e na linguagem com o outro.

\title{
THE RESULTS OF HERMENEUTICS TO THE UNDERSTANDING OF RESEARCH IN EDUCATION
}

\begin{abstract}
The objective of this work is to map the methodological implications of the hermeneutical debate as a comprehensive possibility for the advancement of research in education. The text begins by discussing the paradigm of modernity and a critique of traditional conceptions of language, in view of its incompatibility with some research in the areas of human sciences. Then, it discusses the specificities of education research in Brazil, weaving interpretations about socio-educational phenomena. Finally, it presents the conceptual rigor of hermeneutics that proposes to question the meaning of theories and pedagogical actions in the scope of the research, in order to (de / re) contextualize them to educational practices. The main contributions of hermeneutics to the field of education reveal a sensitivity to the look and speech of the other, whose expressions of cultural relations are constituents of the need to teach the understanding of society itself that encompasses the pedagogical experiences of provoking reflection and understanding of the textual contents, searching for the meanings of the objective, subjective and social reasons that arise in the middle of the pedagogic language. Following the paths of hermeneutics, we learn and teach that in pedagogical rationality we do not deal with the understanding of objects, nor with the comprehension of the totality of objects, but with the whole of our human comprehension in its totality.
\end{abstract}

Keywords: hermeneutics; research in education; understanding.

\section{LOS RESULTADOS DE LA HERMENÉUTICA PARA LA COMPRENSIÓN DE LA INVESTIGACIÓN EN EDUCACIÓN}

\section{Resumen}

El objetivo de este trabajo es mapear las implicaciones metodológicas del debate hermenéutico como posibilidad comprensiva para el avance de las investigaciones en educación. El texto empieza discutiendo el paradigma de la modernidad y una crítica a las concepciones tradicionales de lenguaje, teniendo en vista su incompatibilidad con algunas investigaciones de las áreas de las ciencias humanas. A continuación, discurre sobre las especificidades de la investigación en educación en Brasil, tejiendo interpretaciones sobre los fenómenos socioeducativos. Por último, presenta el rigor conceptual de la hermenéutica que propone cuestionar el sentido de las teorías y acciones pedagógicas en el ámbito de la investigación, a fin de (des / re) contextualizarlas a las prácticas educativas. Las principales contribuciones de la hermenéutica al campo de la educación revelan una sensibilidad para la mirada y el habla del otro, cuyas expresiones de las relaciones culturales son constituyentes de la necesidad de enseñar la comprensión de la propia sociedad que engloba las experiencias pedagógicas de provocar la reflexión y la comprensión de los contenidos textuales, buscando los sentidos de las razones objetivas, subjetivas y sociales que brotan en las entrelíneas del lenguaje pedagógico. Siguiendo por los senderos de la hermenéutica, aprendemos y enseñamos que en la racionalidad pedagógica no tratamos con la comprensión de los objetos, ni con la comprensión de la totalidad de los objetos, sino con el todo de nuestro comprender humano en su globalidad.

Palabras clave: hermenéutica; investigación en educación; la comprensión.

Barbarói, Santa Cruz do Sul, n.53, p.<67-88>,jan./jun. 2019 


\section{REFERÊNCIAS}

ALTMICKS, Alfons Heinrich. Principais paradigmas da pesquisa em educação realizada no Brasil. Revista Contrapontos, v. 14, n. 2, p. 384-397, mai./ago. 2014. DOI: 10.14210/contrapontos.v14n2.p384-397

ANDRÉ, Marli. Pesquisa em Educação: buscando rigor e qualidade. Cadernos de Pesquisa, São Paulo, n. 113, p. 51-64, 2001.

DALBOSCO, Cláudio Almir; SANTA, Fernando Dala; BARONI, Vivian. A hermenêutica enquanto diálogo vivo: contribuições para o campo da pesquisa educacional. Educação, Porto Alegre, v. 41, n. 1, p. 145-153, jan./abr. 2018.

DEVECHI, Catia Piccolo Viero; TREVISAN, Amarildo Luiz. Sobre a proximidade do senso comum das pesquisas qualitativas em educação: positividade ou simples decadência?. Rev. Bras. Educ., Rio de Janeiro, v. 15, n. 43, p. 148-161, Apr. 2010. DOI: http://dx.doi.org/10.1590/S1413-24782010000100010

DEVECHI, Catia Piccolo Viero; TAUCHEN, Gionara; TREVISAN, Amarildo Luiz. Teoria e prática nas pesquisas com formação de professores: uma compreensão aberta à interação comunicativa. Educ. rev., Belo Horizonte, v. 28, n. 4, p. 51-76, Dec. 2012. DOI: http://dx.doi.org/10.1590/S0102-46982012000400003

FLICKINGER, Hans-Georg. A caminho de uma pedagogia hermenêutica. Campinas: Autores Associados, 2010.

GADAMER, Hans-Georg. Verdade e método I: traços fundamentais de uma hermenêutica filosófica. 7. ed. Petrópolis: Vozes; Bragança Paulista: Editora Universitária São Francisco, 2005.

GADAMER, Hans-Georg. Da palavra ao conceito, a tarefa da hermenêutica enquanto filosofia. In: ALMEIDA, Custódio Luís Silva de; FLICKINGER, Hans-Georg; ROHDEN, Luiz (Org.). Hermenêutica filosófica. Nas trilhas de Hans-Georg Gadamer. Porto Alegre: EDIPUCRS, 2000. p. 13-26.

GADAMER, Hans-Georg. O problema da consciência histórica. Rio de Janeiro: FGV, 2006.

GADAMER, Hans-Georg; ALMEIDA, Custódio Luíz Silva de. Hermenêutica filosófica: nas trilhas de Hans-Georg Gadamer. Porto Alegre: Edipucrs, 2000.

GAMBOA, Sílvio Ancisar Sánchez. Pesquisa em Educação: métodos e epistemologias. Chapecó: Argus, 2008.

GATTI, Bernardete A. Algumas considerações sobre procedimentos metodológicos nas pesquisas educacionais. EccoS Rev. Cient., São Paulo, v. 1 , n. 1 , p. 63-79, 1999.

GATTI, Bernardete A. Pesquisar em educação: considerações sobre alguns pontos-chave. Revista Diálogo Educacional, Curitiba, v. 6, n. 19, p. 25-35, 2006. 
HABERMAS, Jürgen. Técnica e Ciência como Ideologia. Trad. Artur Morão. Lisboa: Dom Quixote, 1994.

HABOWSKI, Adilson Cristiano; CONTE, Elaine; PUGENS, Natália de Borba. A perspectiva da alteridade na educação. Conjectura: Filos. Educ., Caxias do Sul, v. 23, n. 1, p. 179-197, jan./abr. 2018. DOI: 10.18226/21784612.v23.n1.10

HEIDEGGER, Martin. Ser e tempo. 4. ed. Petrópolis: Vozes, 2009.

HERMANN, Nadja. Hermenêutica e educação. Rio de Janeiro: DP\&A, 2002.

KUHN, Thomas S. A estrutura das revoluções científicas. 5. ed. São Paulo: Perspectiva, 1998.

MORIN, Edgar. Os setes saberes necessários à educação do futuro. Trad. Catarina Eleonora F. Silva e Jeanne Sawaya. São Paulo: Cortez, 2000.

MORIN, Edgar. Edgar Morin: é preciso educar os educadores. CONTI outra (online). Entrevista concedida à Fronteiras do Pensamento, 2018. Disponível em:

http://www.contioutra.com/edgar-morin-e-preciso-educar-os-educadores/ Acesso em: 11 nov. 2018.

NAJMANOVICH, Denise. O feitiço do método. In: GARCIA, Regina Leite (Org.). Método: Métodos e Contramétodo. São Paulo: Cortez, 2003. p. 25-62.

SANTOS, Boaventura de Sousa. Um discurso sobre as ciências. 5 ed. São Paulo: Cortez, 2008.

SCHMIDT, Lawrence K. Hermenêutica. Trad. Fábio Ribeiro. 3. ed. Petrópolis: Vozes, 2014.

SIDI, Pilar de Moraes; CONTE, Elaine. A hermenêutica como possibilidade metodológica à pesquisa em educação. Revista Ibero-Americana de Estudos em Educação, Araraquara, v. 12, n. 4, p. 1942-1954, out./dez. 2017. Disponível em: 〈http://goo.gl/9ZhvUj〉. Acesso em: 01 set. 2018.

STEIN, Ernildo. Aproximações sobre hermenêutica. Porto Alegre: Edipucrs, 2004.

Data de recebimento: $25 / 09 / 2015$

Data de aceite: 17/06/2019

\section{Sobre as autoras:}

Elaine Conte é Doutora em Educação pela Universidade Federal do Rio Grande do Sul (UFRGS), Professora do Programa de Pós-Graduação em Educação da Universidade La Salle (UNILASALLE) e Líder do Núcleo de Estudos sobre Tecnologias na Educação NETE/CNPq e membro do Grupo de Estudos sobre Filosofia da Educação e Formação de Professores - GEFFOP/CNPq. Endereço Eletrônico: elaine.conte@unilasalle.edu.br 
Cristine Gabriela de Campos Flores é Doutoranda do Programa de Pós-Graduação em Educação da Universidade La Salle - Canoas e bolsista da FAPERGS. Mestre em Educação pelo Centro Universitário La Salle (2016). Possui graduação em Pedagogia (2011) e Especialização em Educação Infantil e Anos Iniciais do Ensino Fundamental (2013). Endereço Eletrônico: cristinegabriela@gmail.com 